\title{
Based on systems science methodology-Research on the talent training system of hall three-dimensional structure
}

\author{
Yong-Chen ${ }^{1, *}$, Zhong Hua-Cheng ${ }^{2, * *}$, Qi-Xü ${ }^{3, * * *}$ \\ ${ }^{1}$ Shijiazhuang Campus, Army Engineering University, Shijiazhuang, 050003, China \\ ${ }^{2}$ Shijiazhuang Campus, Army Engineering University, Shijiazhuang, 050003, China \\ ${ }^{3}$ Shijiazhuang Campus, Army Engineering University, Shijiazhuang, 050003, China
}

\begin{abstract}
Draw lessons from the basic idea of system science methodology, based on the hall three dimensions structure theory construction of research personnel training problems, from the time dimension, logic knowledge and three dimension analysis of all aspects of talent cultivation system, clear the talent training theory support, and solve the problem of a series of contradictions in the process of talent training, further enriched and developed the theoretical system of talents cultivation.
\end{abstract}

\section{INTRODUCTION}

In 1969, American engineer A. D. hall put forward the hall three-dimensional structure method system after summarizing some experience in system engineering [1]. This method is derived from the engineering system problem solving method, making it approximate to the benign structure system. Now it is applied to the construction of the talent training system to study the "soft" problem and make the talent training system more convincing in data.

In order to provide theoretical support for the reform of talent training system, solve a series of contradictions in the process of talent training, and further enrich and develop the theory of education and training. This paper, by using system science methodology of hall three dimensions structure theory to construct the talent training unit for talent cultivation system problem analysis, from the time dimension, logic knowledge and talent training system in the view of the three key problems were analysed, and to improve the personnel training unit starting point and key talent cultivation system, enhance the level of talent ability to post office as soon as possible, to meet the needs of the involved unit of choose and employ persons of talent, but also to meet the urgent needs of society to the appropriate personnel[2] [3].

\section{RESEARCH FRAMEWORK}

This paper puts forward the research framework of talent office-holding ability system based on hall threedimensional structure, which is mainly composed of factor dimension, logic dimension and knowledge dimension [4]. The logic dimension is mainly to explain the meaning of the elements in each element dimension, to explain the rationality of each element design and the optimization of the elements of the logic design; Finally, in order to ensure the completion of each element and step in the above two dimensions, knowledge dimension represents and summarizes relevant knowledge and various professional technologies that need to be applied, as shown in the figure below.

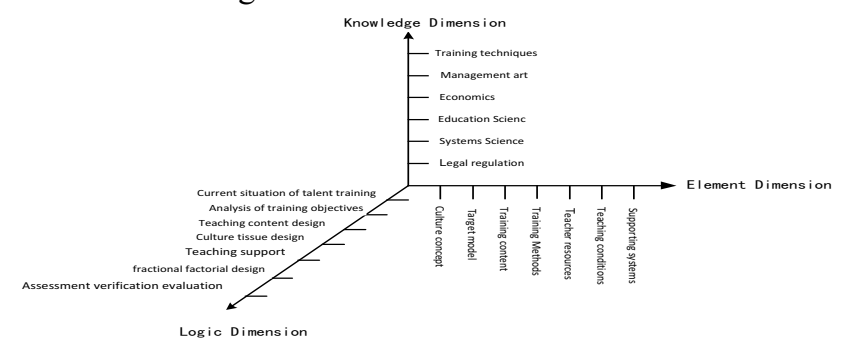

Figure 1 Hall 3d system diagram of talent cultivation

Factor dimension embodies the main components of talent training system. With the change of local enterprises and institutions' demand for talents' ability, training institutions should optimize their own organizational structure around the change of demand for guarantee ability, such as the change of training system efficiency of operational ability. So the factor dimension should include the cultivation idea, the target model, the cultivation content, the cultivation way, the teacher troop, the teaching condition, the supporting system and so on.

Under the premise of logic is in the above elements dimensions, explain the logic of each element of talent cultivation system, namely the elements in constructing the implementation stage of the logical steps, mainly is the social status quo analysis, analysis of the target type

\footnotetext{
*Corresponding author's e-mail:qq675618842@163.com

**Corresponding author's e-mail:cbenyong330515@163.com

***Corresponding author's e-mail:2661524650@qq.com
} 
elements, content analysis, organization design, the support capability to support, to evaluate content and implementation of validation division [5].

Knowledge dimension is embodied in the supporting theory of talent training system and related technical guarantee. It mainly includes the knowledge and theoretical technology of education, management art, economics, social science, system science, law and regulations and so on. Table 1 provides a more intuitive representation.

\section{TABLE I. 3D COMPARISON TABLE OF TALENT} TRAINING SYSTEM

\begin{tabular}{c|c|c}
\hline Dimension & $\begin{array}{c}\text { Intrasystem } \\
\text { action }\end{array}$ & Mainly containing elements \\
\hline $\begin{array}{c}\text { Element } \\
\text { dimension }\end{array}$ & $\begin{array}{c}\text { It is the main } \\
\text { component of } \\
\text { talent training } \\
\text { system }\end{array}$ & $\begin{array}{c}\text { Training concept, target model, } \\
\text { training content, training mode, } \\
\text { teaching staff, teaching } \\
\text { conditions, supporting system }\end{array}$ \\
\hline $\begin{array}{c}\text { Logic } \\
\text { dimension }\end{array}$ & $\begin{array}{c}\text { A logical program } \\
\text { that explains the } \\
\text { elements of a } \\
\text { system }\end{array}$ & $\begin{array}{c}\text { Social status analysis, target type } \\
\text { analysis, content element } \\
\text { analysis, organization design, } \\
\text { guarantee ability support, } \\
\text { assessment and evaluation } \\
\text { content, and verification of } \\
\text { branch implementation }\end{array}$ \\
\hline $\begin{array}{c}\text { Knowledge } \\
\text { dimension }\end{array}$ & $\begin{array}{c}\text { System support } \\
\text { theory and related } \\
\text { technical support }\end{array}$ & $\begin{array}{c}\text { Training technology, education, } \\
\text { management art, economics, } \\
\text { system science, legal knowledge }\end{array}$ \\
\hline
\end{tabular}

\subsection{The essential dimension of talent training system}

The analysis of the elements shown in the hall $3 \mathrm{~d}$ system diagram of talent cultivation in figure 1 shows that the elements mainly include the cultivation concept, target model, cultivation content, cultivation mode, faculty strength, teaching conditions, supporting system, etc. See figure 2 for details.

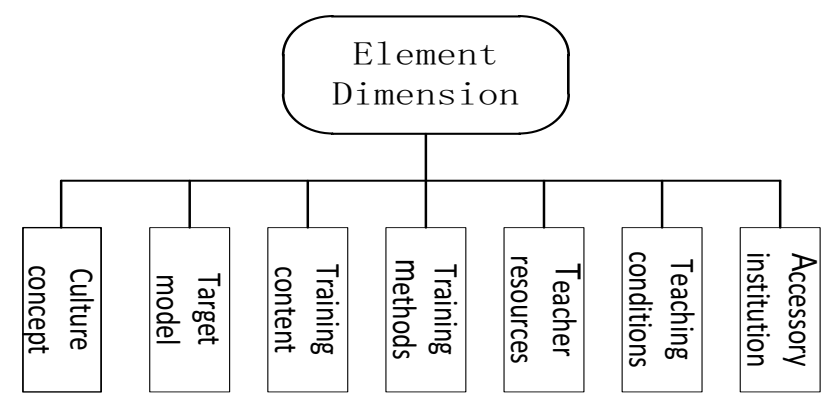

Figure 2 Element dimension components

- Cultivate ideas. The cultivation idea is the basic premise in the personnel cultivation education. Firstly, the advanced training concept is established to guide the construction of hardware and software in the education system and the training system, so as to provide theoretical guidance for the construction of a correct talent training system for education talents and training ability.

- Target model. The talent training objective model refers to the training objectives and requirements that the relevant personnel should achieve after training in institutions such as colleges and universities. This element plays a key role in the talent training system and plays a guiding role.

- Training content. The training content is the teaching plan developed by the institutions of colleges and universities, and is the basic basis for the methods and methods of training organizations. The training content should take into full consideration the demand of the personnel's office-holding ability in the environment and motivation under specific circumstances to ensure the adaptability of the personnel training and the types of personnel needed.

- Training methods. The cultivation way is the concrete implementation method and means to realize the cultivation goal and the cultivation content throughout the whole process.

- Teachers. Teachers are in the process of talent training talents, the basis of the conditions of capital equipment and so on, is the guarantee of implementation for training conditions, it includes teachers, management team, capital equipment investment, etc.

- Teaching conditions. Teaching conditions are the necessary guarantee conditions for learning materials, training sites, training facilities, experimental equipment and educational equipment that need to be provided in the process of talent training, and they are also the material basis for talent training. Only by establishing suitable and perfect teaching conditions can we effectively guarantee teaching and ensure the effect of talent training.

- Improve the supporting mechanism. The supporting mechanism is to provide a formal guarantee for the talent training system. On talent training, not only for education training system of teaching hardware and management of the organization system optimization, need more healthy and effective, scientific and normative operation system as the mechanism guarantee, from the teaching goal setting, teaching organization and management, teaching steps to implement each link, improving the capacity of talent cultivation system of high quality.

Through the optimization of the above factors, the factors in the factor dimension are optimized to achieve the goal of giving full play to the efficiency of the education and training system, and even comprehensively improving the ability to train.

\subsection{The logical dimension of talent training system}

The logical dimension refers to the logical steps for the establishment and optimization of the elements in the talent training system. It mainly includes seven steps, including the analysis of the current situation of talents, the analysis of training objectives, the design of educational content, the design of training organization, the support of teaching, the assessment, verification and evaluation, and the summary of the distribution of results 
[6]. The logical relationship among these seven steps can be reflected in the following figure:

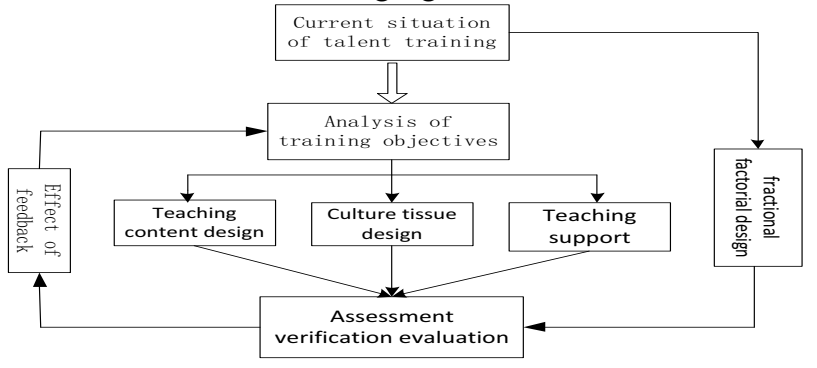

Figure 3 The logical dimension diagram of talent training

- Talent status analysis. The analysis of the current situation of talent training system is a specific analysis of the actual situation of the development of each element of the talent training system at home and abroad, so as to grasp the current state and development trend of such talent training at home and abroad, and provide specific basis and theoretical basis for the construction of each element of talent training.

- Analysis of training objectives. The analysis of training objectives is based on the analysis and trend prediction of the current education and training system, including its internal specific situation and external factors, which can provide decision-making basis for the future development direction of various elements of talent training. Through the analysis of training objectives, it can provide a reliable basis for the design of educational contents related to each element of the talent training system.

- Educational content design. Content design is a specific description of the elements of the training system, such as training objective model, teaching content, teaching staff, teaching conditions and other specific construction content.

- Culture tissue design. Organizational design is the means and process design to achieve the objectives and contents of the construction, and the design of the specific organizational implementation of the construction contents.

- Teaching support. The guarantee support is the material basis to realize the construction goal of each element of talent training and provides the conditions for the smooth implementation of construction activities.

- Assessment, verification and evaluation. Education and training is a complex system engineering, the maturity of the model involved and the effectiveness of the education activities will have a great impact on the effect of education and training, through the verification, can avoid setbacks, and then determine the feasibility of the system construction program.

- The system is implemented step by step. Step by step implementation of the system refers to the process of carrying out some systematic trials in the process of talent training, further summarizing and evaluating the experience and lessons learned in the pilot process, correcting all elements in the talent training system, perfecting the whole training system through continuous improvement, and achieving optimization.

\subsection{Talent training system knowledge dimension}

The knowledge dimension of the talent training system is the knowledge and technology used by each element in each logical stage of the education and training system [7]. Talent training involves the theories and techniques including many aspects, culture system need to rely on a variety of subject knowledge, we can according to the elements of the system properties, can identify the personnel training system can be involved in training technology, pedagogical knowledge, system science, management, art, economics and legal knowledge, etc., all kinds of knowledge and technology influence each other as shown in figure 4 :

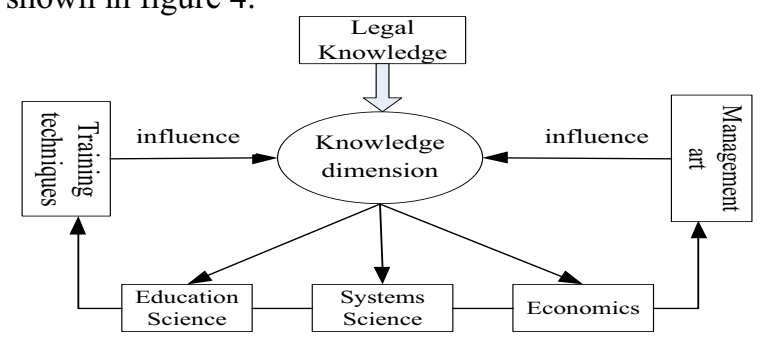

Figure 4 The influence diagram of knowledge dimension elements

The training technology can be applied to the training theory of the position, the optimization and design of the target model and the training content of the subject, and provide theoretical guidance for the design of the talent training system.

Pedagogical knowledge can be used to guide and solve the problems encountered in the process of personnel training, provide scientific basis for personnel training, and have a detailed understanding of professional knowledge, in order to cultivate talents suitable for the industry.

System science is used to solve the macro guidance in talent training, provide methodological guidance for education and training, and realize the comprehensive, systematic and overall optimization of education and training.

The art of management can be used to solve the problems in talent training, such as making plans, organizing work, knowing leadership, having coordination ability and controlling ability, and providing management techniques and means for completing education and training.

Economic knowledge is used to solve the problem of budget and economic optimization in talent training, so that the transformation of talent training meets the requirements of education and construction.

\section{ConClusion}

This paper makes a preliminary study on the problem of personnel training by using the holl three-dimensional 
structure methodology, puts forward the analysis of each link of personnel training, defines the theoretical support of personnel training, solves a series of contradictions in the process of personnel training, and further enriches and develops the theoretical system of education and training.

\section{REFERENCES}

1. Shi quan,Shi xianming,etal. (2016) System decision and modeling [M]. National defense industry press, Beijing.

2. Shi xianming, jiang guangsheng. (2019) Research on the comprehensive quality training system of undergraduate cadets based on hall's three-dimensional structure. Modern education. 25 $134-135$.
3. Che li. (2013)Research on college students' training system based on hall's three-dimensional structure $[\mathrm{J}]$. China youth student research. $10: 70-73$.

4. Zhao mei, wang lixin, shi xianming. (2012) A system model for the promotion and transformation of scientific and technological achievements in colleges and universities based on hall's threedimensional structure. Value engineering, 31: 237-238.

5. Shi xianming, xiang kaiquan, zhu dunxiang etal. (2012) Capacity building analysis of "double-member" faculty based on hall three-dimensional structure. The Science Education Article Collects.25: 43-44

6. Shi xianming, zheng hui, wang lixin etal. (2016) Research on equipment reliability growth system framework based on hall three-dimensional structure. Equipment construction and development, Shijiazhuang.

7. Yue zhiyong, ding hui.( 2013) Research on training system of technology innovation methods based on hall three-dimensional structure. Research on scientific management, 5:22-24. 